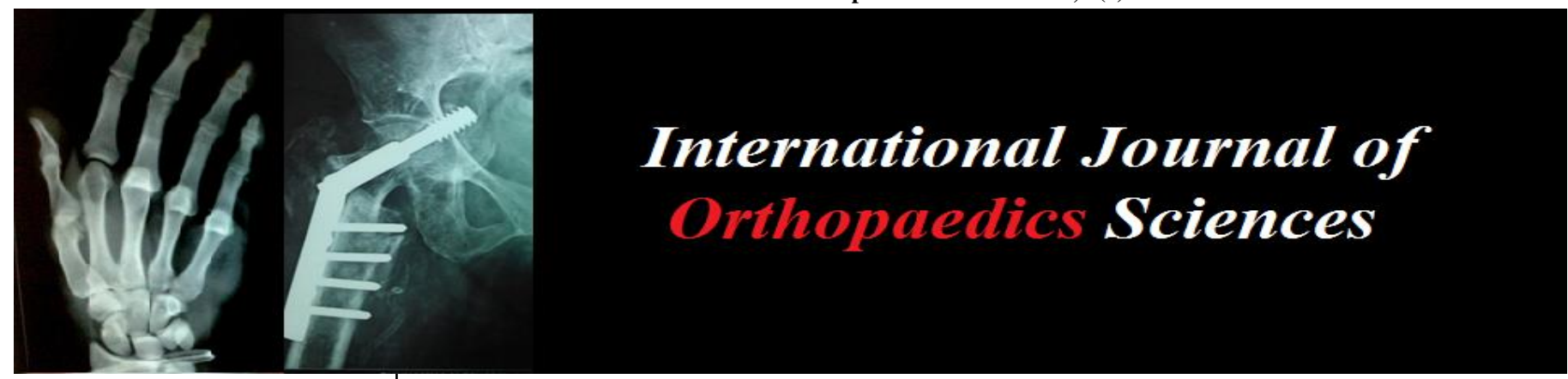

E-ISSN: 2395-1958

P-ISSN: 2706-6630

IJOS 2020; 6(1): 79-82

(C) 2020 IJOS

www.orthopaper.com

Received: 18-11-2019

Accepted: 22-12-2019

Gaurav Kumar Gupta

DNB Ortho, Senior Resident,

Department of Orthopedics, Rao

Tula Ram Hospital, Delhi, India

Rejo Varghese Jacob

DNB Ortho, Senior Resident,

Department of Orthopedics,

Hindu Rao Hospital \& NDMC

Medical College, Delhi, India

Corresponding Author:

Rejo Varghese Jacob

DNB Ortho, Senior Resident,

Department of Orthopedics,

Hindu Rao Hospital \& NDMC

Medical College, Delhi, India

\section{Demographic profile and functional outcome following fixation of distal femur fractures by locking compression plate}

\section{Gaurav Kumar Gupta and Rejo Varghese Jacob}

DOI: https://doi.org/10.22271/ortho.2020.v6.i1b.1843

\section{Abstract}

Fractures involving the distal femur are common injuries accounting for 4-7\% of all femur fractures with almost 58\% having intraarticular extension. These fractures are common in young males following highvelocity injuries and are also seen in older osteoporotic individuals. We present a series of 30 patients sustaining distal femur fractures to study their demographic profile and functional outcome following open reduction and fixation using locking compression plate. The patients were followed up for a period 6 months and functional outcome was assessed using Neer scoring system. In our study, 12 patients had "excellent" outcome (40\%), 7 patients showed "good" outcome (23.3\%), 8 patients had "fair" outcome $(26.7 \%)$ and 3 patients "poor" outcome $(10 \%)$. From our analysis, it was observed that Locking Compression Plate shows good results in extra-articular, intra-articular and comminuted fractures irrespective of age of patient, comorbidities and delay in surgery. Articular congruity must be maintained during surgery to improve the functional outcome in cases of intra-articular extension and early nonweight bearing mobilization is the key for better long term results along with careful partial weight bearing.

Keywords: Locking compression plate, Neer scoring system, swashbuckler approach, early mobilization

\section{Introduction}

Distal femoral fractures are defined as fractures upto $15 \mathrm{~cm}$ from distal femoral articular surface $^{1}$ with an incidence of $4-7 \%$ among all femur fractures ${ }^{[2]}$. These fractures have a bimodal age distribution involving young males following high-energy accidents and older osteoporotic individuals especially females following low-energy falls ${ }^{[3]}$. The distal femur fractures are classified by Muller et al. and expanded by AO/OTA as extra-articular, partial articular and complete articular. It is very useful in determining treatment and prognosis ${ }^{[4]}$.

Prior to 1970, distal femur fractures were treated conservatively leading to angular deformities, knee joint incongruity and knee stiffness ${ }^{[5,6]}$. In the 1970's and early 1980's non-locking plates came into preference but these lead to high rate of infections, non-union and stiffness ${ }^{7}$. $95^{0}$ blade plate, condylar buttress plates and supracondylar interlocking nails were also used but there use was limited to simple extra-articular fractures and failed in complex intraarticular and comminuted extra-articular fractures ${ }^{[2]}$.

Distal femoral locking compression plate allows both locking and compression screw fixation of the femur shaft and condyles in a multiaxial fashion. These plates are designed to preserve local biology and avoid problems with fracture healing and infection ${ }^{[8,9]}$. The Locking Compression Plate system is a very versatile system which offers a number of advantages in fracture fixation. However, the system is complex and a careful attention to a number of potential pitfalls need to be considered, including implant breakage or loosening ${ }^{[10]}$.

\section{Materials and Methods}

30 patients sustaining distal femur fractures attending the Department of Orthopedics during the period from 2016 to 2019 were subjected to this study and were followed up for a period of 6 months. Detailed history was taken noting the mode, severity, event and type of trauma. All the required routine investigations and radiological examination was done. 
Fracture was classified and the patient was planned for surgery. Those patient's who were not fit for surgery were kept on upper tibial skeletal traction until anaesthetic fitness was obtained. Patient information was collected and compiled.

\section{Inclusion Criteria}

1. Post-traumatic cases.

2. All closed fractures and Type1 open (Gustilo and Anderson).

3. Patients fit for surgery.

\section{Exclusion Criteria}

1. Patients who do not give consent or unable to take part in post-operative rehabilitation.

2. Infected wounds and open fractures (type 2 and 3 ).

3. Pathological Fractures.

4. Cases with severe distal neurovascular defect.

\section{Operative procedure}

The patient was operated under spinal/general anaesthesia in supine position with knee held in slight flexion. Extensile lateral approach or Swashbuckler approach was used followed by gentle dissection and retraction to reach the fracture site. Articular fragments were reduced and provisionally fixed with kirshner wires. Proximal and distal fragments were held under reduction and fixed with Distal Femur Locking Compression Plate. A minimum of 5 screws including lag screws and locking head screws were held in the distal fragment and a minimum of 4 screws were held to the proximal fragment. Post-operative arthrotomy wound was sutured and skin closure done after obtaining complete hemostasis and aseptic dressing given.

The patient was started on non-weight bearing knee flexion and extension exercises for 4 weeks post surgery. Partial weight bearing was started at 6 weeks followed by full weight bearing by 12 weeks.

\section{Results and Discussion}

After compiling the proforma, the patients were followed up at 4 weeks, 2 months and 6 months. Functional outcome was assessed at 6 months using Neer scoring system. The following were the results of the study.

\section{Age distribution}

The patients ranged from 21 to 71 years with a mean age of 39.5 years. Most of the patients $(63.3 \%)$ were <40years old.

\section{Gender distribution}

Males were found to be more affected in present series $(83.3 \%)$.

\section{Mode of injury}

$73 \%$ cases were due to Road Traffic Accidents, making it the most common cause by far. Other causes were fall, either from height or by slip on ground.

\section{Type of fracture}

There was almost equal distribution among intra-articular (16 cases) and extra articular fracture (14 cases).

\section{Classification of fracture}

The fractures were classified based on AO/OTA classification. Highest distribution was of $\mathrm{C} 2$ type followed by $\mathrm{A} 1$ and $\mathrm{A} 2$ types.

\section{Presence of comminution}

Of the 30 patients, 20 patients had comminuted fractures. Most of the comminuted fractures were seen in patients less than 60 years and males. The mode of injury in most of these comminuted fractures was Road Traffic Accident (17 cases).

\section{Injury to surgery interval}

In the present series duration between injury and surgery varied from being operated after 1 day to 20 days. The mean injury surgery interval was 7.67 days. This period of delay was utilized towards making the patient fit for surgery besides reduction in preoperative swelling.

\section{Complications}

1 patient developed skin necrosis requiring debridement and antibiotics. 3 patients developed superficial skin infection which healed in 2 weeks with antiseptic dressing and antibiotics.

\section{Functional Outcome}

Functional outcome was assessed using Neer scoring system at 6 months of follow up. 12 patients had "excellent" outcome (40\%), 7 patients showed "good" outcome (23.3\%), 8 patients had "fair" outcome $(26.7 \%)$ and 3 patients "poor" outcome $(10 \%)$.
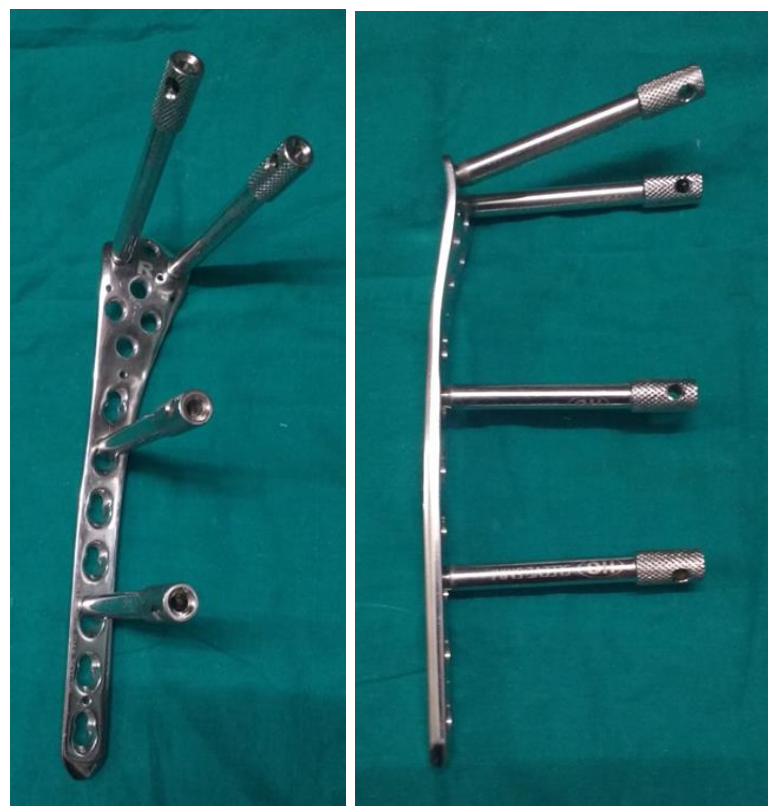

Fig 1: Locking Compression Plate

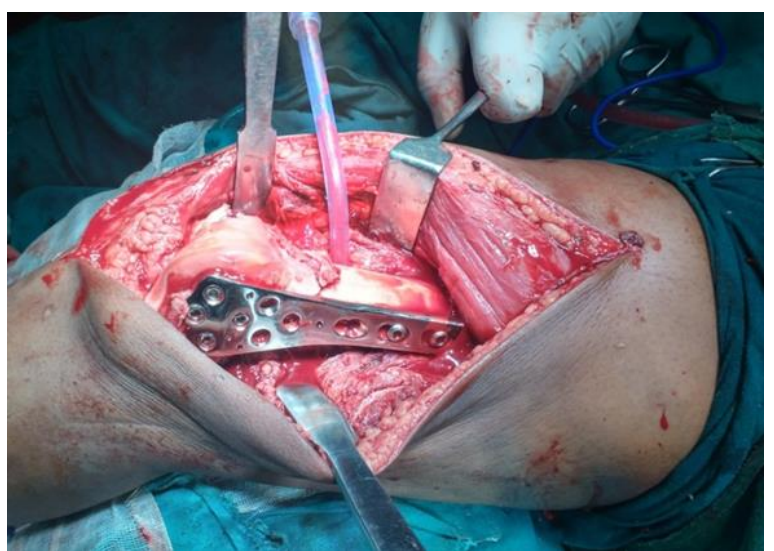

Fig 2: Intra-operative image showing fixation with locking compression plate 


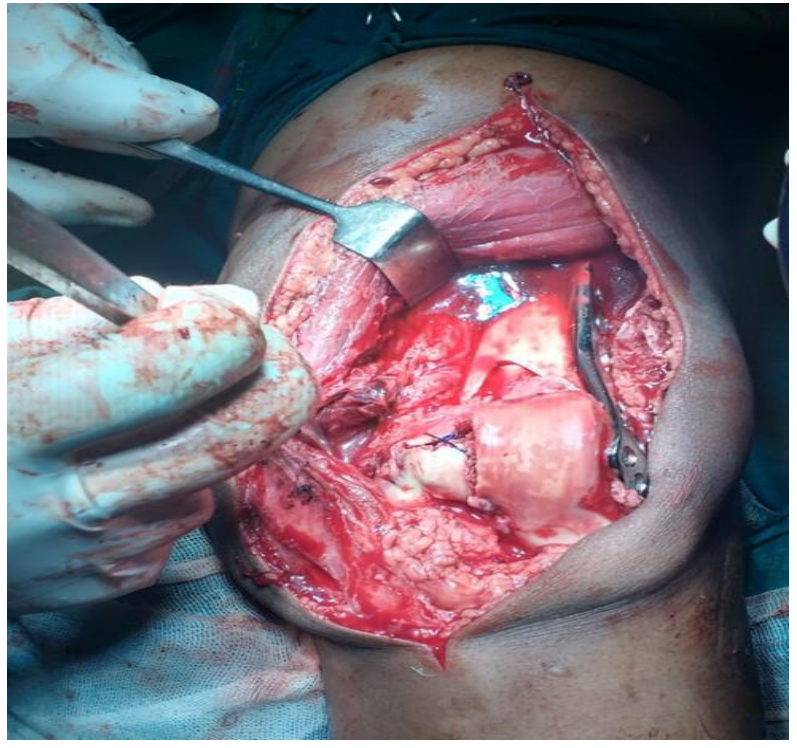

Fig 3: Intra-operative image showing fixation with locking compression plate
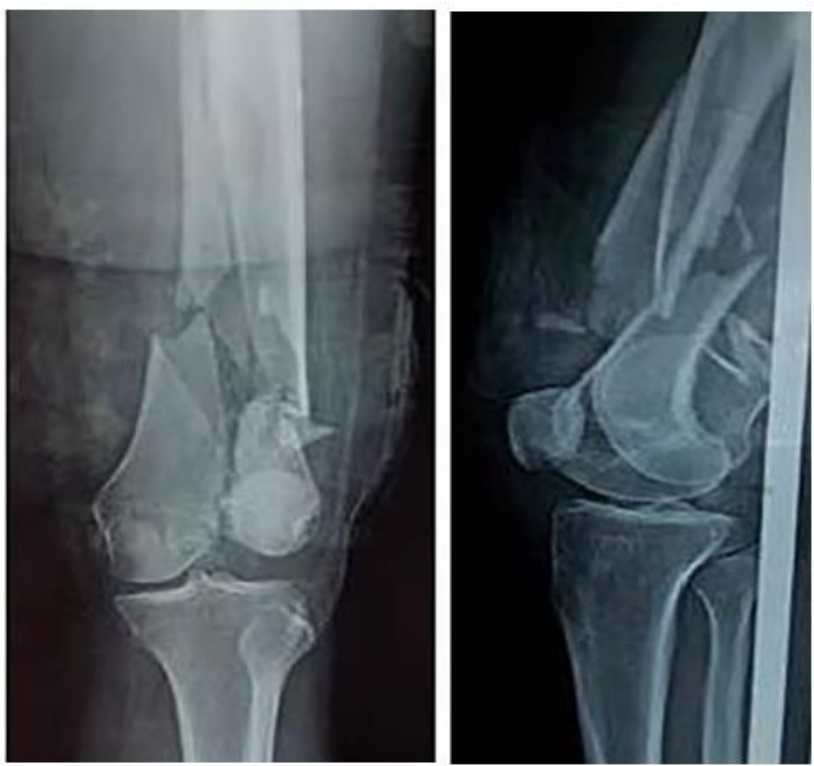

Fig 4: Pre-operative radiograph Anteroposterior and lateral view distal femur fracture with intra-articular extension
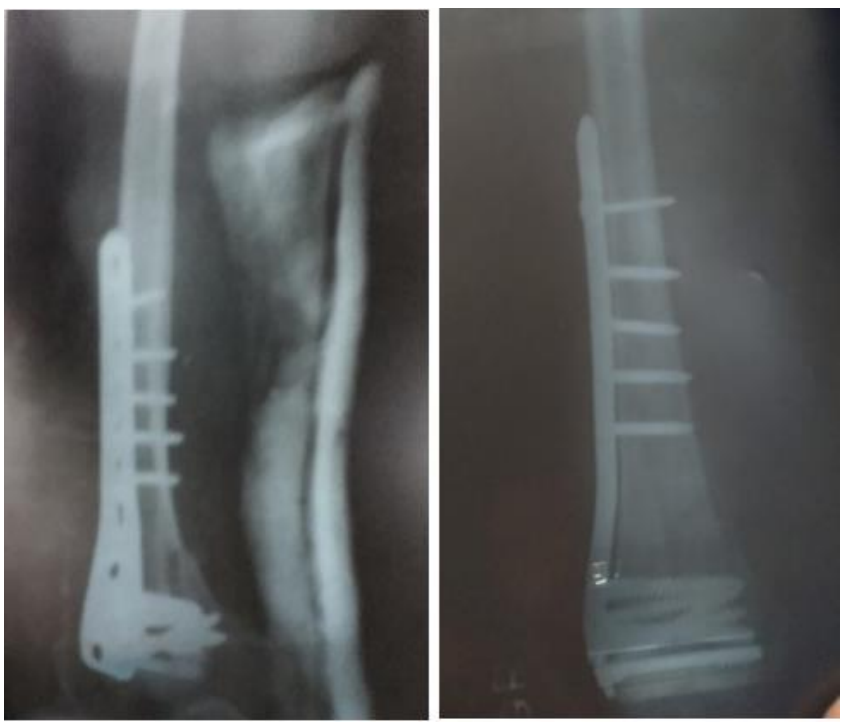

Fig 5: Post-operative radiograph Anteroposterior and lateral views after fixation with Locking Compression Plate
Table 1: Age Distrubution

\begin{tabular}{|c|c|c|}
\hline Age group & No of patients & Percentage \\
\hline$<40 \mathrm{yrs}$ & 19 & 63.3 \\
\hline $40-60 \mathrm{yrs}$ & 7 & 23.4 \\
\hline$>60 \mathrm{yrs}$ & 4 & 13.3 \\
\hline Total & 30 & 100 \\
\hline
\end{tabular}

Table 2: Mode of Injury

\begin{tabular}{|c|c|c|}
\hline Mode of injury & No of patients & Percentage \\
\hline RTA & 22 & 73.3 \\
\hline Fall by slip & 5 & 16.7 \\
\hline Fall from height & 3 & 10 \\
\hline Total & 30 & 100 \\
\hline
\end{tabular}

Table 3: Classification of fracture

\begin{tabular}{|c|c|c|c|c|c|c|c|c|}
\hline & A1 & A2 & B2 & C1 & C2 & C3 & A3, B1, B3 & Total \\
\hline No of patients & 7 & 7 & 2 & 3 & 10 & 1 & 0 & 30 \\
\hline Per cent & 23.3 & 23.3 & 6.7 & 10 & 33.3 & 3.3 & 0 & 100 \\
\hline
\end{tabular}

Table 4: Assessment of comminution

\begin{tabular}{|c|c|c|c|c|c|c|}
\hline & \multicolumn{2}{|c|}{$\begin{array}{c}\text { Age } \\
\text { distribution }\end{array}$} & \multicolumn{2}{c|}{$\begin{array}{c}\text { Gender } \\
\text { distribution }\end{array}$} & \multicolumn{2}{c|}{$\begin{array}{c}\text { Mode of } \\
\text { injury }\end{array}$} \\
\cline { 2 - 7 } & $<60 y r s$ & $>=60 y r s$ & Male & Female & RTA & $\begin{array}{c}\text { Non } \\
\text { RTA }\end{array}$ \\
\hline $\begin{array}{c}\text { Non } \\
\text { comminuted }\end{array}$ & 6 & 4 & 7 & 3 & 5 & 5 \\
\hline Comminuted & 17 & 3 & 18 & 2 & 17 & 3 \\
\hline
\end{tabular}

Table 5: Functional outcome by Neer scoring system

\begin{tabular}{|c|c|c|}
\hline & No of patients & Percentage \\
\hline Poor $(<55)$ & 3 & 10 \\
\hline Fair $(55-69)$ & 8 & 26.7 \\
\hline Good $(70-85)$ & 7 & 23.3 \\
\hline Excellent $(>85)$ & 12 & 40 \\
\hline Total & 30 & 100 \\
\hline
\end{tabular}

The purpose of this study is to evaluate the functional outcome after fixation of distal femur fractures using Distal Femur Locking Compression Plate and the various preoperative and post-operative factors affecting the final result. $63 \%$ of the patients in our study were below 40 years of age. The forces required to produce a distal femur fracture is considerable and rarely generated by trivial trauma, so the most common etiology remain Road Traffic Accident which is more common in this age group as validated by multiple studies around the globe. A similar pattern of age distribution was found in study by Panchal et al. ${ }^{[11]}$ and Gawali SR ${ }^{[12]}$.

$83 \%$ of the patients in our study were males, which is in congruence with study of Panchal et al. ${ }^{[11]}$ who had 16 out of 20 patients as males. This may be due to prevalent social custom in the country where males have a more active outdoor life.

$73 \%$ cases were due to Road Traffic Accident. People above 60 years were significantly associated with fall. These associations were reciprocated in the study by Kregor PJ et al, who had 33 out of 50 patients with history of Road Traffic Accident ${ }^{[13]}$. $(66 \%)$.

In our study, highest distribution was of $\mathrm{C} 2$ type fracture followed by A1 and A2 types. As in reported series by Panchal et al. ${ }^{[11]}$, intercondylar and/or comminuted fractures are most common as they commonly occur after Road Traffic Accidents which is the most common etiology for distal femur fractures. Road Traffic Accidents were significantly associated with comminution in our study, similar to the 
observations of Thomson $\mathrm{AB}$ et al. ${ }^{[14]}$. The high velocity trauma during Road Traffic Accident leads to comminution.

Over $80 \%$ patients were operated within 2 weeks. Patients above 60 years were significantly associated with delay in surgery compared to younger age group. Elderly patients are often not financially independent and their treatment decisions are often taken by other family members. Also elderly patients suffer from comorbidities leading to possible delay in anesthetic clearance, which is supported by study by Ricci WM et al. ${ }^{[15]}$.

According to Neer scoring system, 19 patients (63\%) had good to excellent results and only $10 \%$ patients had poor result. This was in concordance to study conducted by Trivedi NP et al. ${ }^{[16]}(68 \%)$. Other studies by Gawali SR et al. ${ }^{[12]}$ and Panchal $\mathrm{P}$ et al. ${ }^{[11]}$ showed better functional outcome compared to our study.

\section{Conclusion}

From our analysis, it is observed that Locking Compression Plate shows good results in extra-articular, intra-articular and comminuted fractures irrespective of age of patient, comorbidities and delay in surgery. Articular congruity must be maintained during surgery to improve the functional outcome in cases of intra-articular extension. Early nonweight bearing mobilization is the key for better long term results along with careful partial weight bearing.

\section{Acknowledgements}

All the staff, residents and faculty of Department of Orthopedics and Physical and Mental Rehabilitation, Hindu Rao Hospital and NDMC Medical College, Delhi.

\section{References}

1. Rockwood and Green's. Fractures in Adults: Supracondylar femur fracture, 2.

2. Borthakur B, Hanse B, Haque R, Jindal S, Talukdar M. Results of Locking Compression Plate fixation in Distal Femur Fractures: A Prospective Study. Journal of Medical Thesis. 2016; 4(1):31-36.

3. Shriharsha RV, Sapna M. Utility and outcomes of locking compression plates in distal femoral fractures. Int J Res Orthop. 2015; 1(1):15-21.

4. Koval KJ, Zuckerman JD. Handbook of fractures. 3rd ed. Philadelphia: Lippincott Williams \& Wilkins, 2006.

5. Schütz M, Müller M, Krettek C, Hontzsch D, Regazzoni $\mathrm{P}$, Ganz R et al. Minimally invasive fracture stabilisation of distal femoral fractures with the LISS: a prospective multicenter study. Results of a clinical study with special emphasis on difficult cases. Injury. 2001; 32:48-54.

6. Tscherne H, Trentz O. Recent injuries of the femoral condyles. Langenbecks Arch Chir. 1977; 345:396-401.

7. Herrera DA, Kregor PJ, Cole PA, Levy BA, Jönsson A, Zlowodzki M. Treatment of acute distal femur fractures above a total knee arthroplasty: systematic review of 415 cases (1981-2006). Acta Orthop 2008; 79:22-27.

8. Parker DA, Lautenschlager EP, Caravelli ML, Flanigan DC, Merk BR. A Biomechanical Comparison of Distal Femoral Fracture Fixation: The Dynamic Condylar Screw, Distal Femoral Nail, Locking Condylar Plate, and Less Invasive Stabilization System, 2005.

9. Krettek C, Muller M, Miclau T. Evolution of Minimally Invasive Plate Osteosynthesis (MIPO) in the femur. Injury. 2001; 3:14-23.

10. Sommer C, Babst R, Müller M, Hanson B. Locking Compression Plate Loosening and Plate Breakage: A
Report of Four Cases. 2004; 18(8):571-577.

11. Panchal P, Patel C, Poptani A. Treatment of distal end of fracture femur by locking compression plate. Int $\mathrm{J}$ of Med Sci Public Health. 2016; 5(9):1754-1758.

12. Gawali SR, Gajanan KM, Bhosage M, Niravane PV. Management of Fractures of Distal Femur. Journal of medical thesis. 2015; 3(2):31-35.

13. Kregor PJ, Stannard JP, Cole PA, Zlowodski M, Alonso JA. Distal femoral fracture fixation utilizing the Less Invasive Stabilization System (L.I.S.S.): the technique and early results. 2001; 32(3):SC32-SC47.

14. Thomson AB, Driver R, Kregor PJ, Obremskey WT. Long-term functional outcomes after intra-articular distal femur fractures: ORIF versus retrograde intramedullary nailing. Orthopedics. 2008; 3:748-750.

15. Ricci WM, Loftus T, Cox C, Borrelli J. Locked plates combined with minimally invasive insertion technique for the treatment of periprosthetic supracondylar femur fractures above a total knee arthroplasty. J Orthop Trauma. 2006; 20:190-196.

16. Trivedi NP et al. Int J Res Orthop. 2015; 1(1):22-27. 